\title{
DISCURSO POLÍTICO Y VERDAD
}

\section{FEDERICO REyes Heroles}

INSTITUTO DE INYESTIGACIONES JURÍDICAS Universidad Nactonal AUTónoma de México

Uno de los múltiples beneficios que ha traído la destrucción sistemática de los mitos y estigmas que colgaban, que se habían prendido, alrededor del fenómeno del conocimiento, es la posibilidad, no individual sino colectiva, de un acto análogo al de la toma de conciencia hegeliana. Contemplar una determinada producción de conocimiento, en sus muy variados tipos, ${ }^{1}$ lleva a reconocer una dinámica ajena, que funciona independientemente de nuestras concepciones particulares o deseos al respecto. Este primer paso -el reconocimiento de lo otro con sus límites y fronteras - supone a la vez poder contemplarse en una determinada dinámica dentro de la cual se produce, o por lo menos se pretende que se produce, conocimiento.

El eje del razonamiento, que ha sido desarrollado por varios autores, centra la discusión alrededor del aval que una comunidad ${ }^{2}$ extiende sobre una determinada forma de conocimiento. Este aval puede, a su vez, sustentarse en razones que tienden más bien hacia la diversidad que a cualquier uniformidad, uniformidad que destaca entonces como deseo académico antes que realidad. En esta vía pareciera que los fenómenos que se convierten en objeto de conocimiento al momento de establecerse la relación con la comunidad que extiende un aval, de alguna manera

1 Para un planteamiento claro y moderno puede consultarse: Villoro, Luis, Creer, saber, conocer, Siglo XXI Editores, S. A., primera edición, 1982. En particular el capítulo décimo "Tipos de conocimiento", en el cual el autor presenta un breve recorrido por las diversas formas de conocimiento y por ende de las distintas comunidades que lo avalan. Desde sapienciales hasta aquellas comunidades con pretensión cientifica.

2 La expresión utilizada por Kuhn es la de "comunidad científica pertinente", Kuhn, T. A., La estructura de las revoluciones cientificas, Fondo de Cultura Económica. Breviarios 213, segunda reimpresión 1975, p. 86.

Ulises C. Moulines la retoma como "comunidades científicas", véase: Moulines, Ulises C., Exploraciones metacientificas, Alianza Editorial, S. A. Colección "Textos", Madrid 1982, p. 113.

Villoro utiliza el término de "comunidades epistémicas" y posteriormente el de "comunidades sapienciales" para las apreciaciones centradas en el saber. Villoro, L., op. cit., p. 246. 
determinan, por lo menos parcialmente, las normas en las cuales se sustentan y justifican, los razonamientos de los cuales se desprende la afirmación del conocimiento. La interrelación entre sujeto y objeto de conocimiento establece especificidades que para el caso pareciera ser prudente retomar por vía de las comunidades epistémicas que avalan, y de las pretensiones de los sujetos.

El acto de confirmación de conocimiento regresa primero a parámetros personalizados, subjetivos: alguien conoce. A partir de una serie de supuestos muy diversos, que van desde la mayor confrontación empírica hasta la más exótica de las vivencias, pareciera ser necesario atravezar por un tamiz vivencial, biográfico-social, que permite arribar a la afirmación del conocimiento. ${ }^{3}$ Este proceso contendría tres momentos analíticos; la afirmación de conocimiento sin aval que puede transformarse en avalada y que puede llegar a convertirse, a su vez, en otorgadora de aval. Téngase presente que el aval que transforma la afirmación de conocimiento en conocimiento confirmado es, con frecuencia, de indole totalmente personal, aunque de manera subyacente se encuentra una comunidad que previamente ha avalado.

Ahora bien, la comunidad que otorga el aval supone intersubjetividad reconocida. El aval es comunitario a partir de ciertos supuestos de rigor determinados fundamentalmente por la materia que se pretende conocer. La enología dista de la etnología por mucho más que una letra. El conocimiento en este sentido está cruzado por un doble eje; por un lado el de la temporalidad: para tal momento alguien conoce sobre $\mathbf{X}$ cuestión. Por el otro, un eje social dados los vínculos que subyacen y la conformación grupal, a la comunidad pertinente de que se trate. Toda afirmación de conocimiento que se lleva adelante y que puede llegar a ser confirmada como tal, pues ha sido avalada por la comunidad pertinente ${ }^{-}$en la materia, está sostenida por un andamiaje complejo de relaciones sociales. El relevo paradigmático supone pequeñas revoluciones sociales.

A partir de esta mecánica, dos rutas opuestas, de razonamiento contrapuesto, parecieran entrar en tensión. En el extremo, al explicar el conocimiento como fenómeno histórico social, de avales comunitarios, en cierto sentido podríamos regresar a un mundo de brujos, de conocedores, para seguir utilizando el mismo lenguaje; conocedores que se

3 Elías Canetti hace referencia a varios ejemplos de cómo las comunidades van reconociendo jefatura o liderazgo en determinadas personas, dependiendo de la experiencia vital de estas, llegando a convertirse las mismas en las fuentes originales de diversos poderes. Véase: Canetti, Elías, Masa y poder, Muchnik Editores, S. A. Barcelona 6, tercera edición 1981, cap. "El superviviente".

- El ejemplo de los catadores de vino como caso extremo de comunidad sapiencial es presentado por Villoro. Villoro, L., op. cit., p. 241. 
encuentran al final de una larguísima trayectoria profesional y también de inserción en una comunidad y que son los que van extendiendo paso a paso los créditos que permiten, en tracto sucesivo, ascender al conocimiento que sólo cobra sentido por el reconocimiento social. Las formas de aval son profundamente diferenciadas y van desde la observación sobre el manejo de un instrumental en un quirófano, que efectivamente puede ser comprobable como mecanismo idóneo de selección de los sujetos que pueden llegar a producir conocimiento, hasta la obligación, en ocasiones ridículas, de presencia física de un determinado sujeto en situaciones que se consideran como parte del aprendizaje. En vía de razonamiento radical, llevado al absurdo, nadie escapa a una vertiente caprichosa del conocimiento como experiencia profesional y vivencial. ${ }^{5}$

La forma de contraargumentar a esta versión radical del conocimiento como aval de los conocedores encuentra, en el otro lado del espectro, razonamientos sustentados en mediaciones fácticas que van variando como parámetro. Aquí la intención predominante es presentar al productor de conocimiento como producto de una ruta profesional, preestablecida y no sujeta a caprichos personales. Al final de la ruta se pretende poder demostrar que el sujeto que se va a avalar como profesional, como conocedor, ha demostrado fácticamente su capacidad para resolver determinadas situaciones dentro de una vertiente de interpretación.

Sin embargo, como ha sido demostrado ampliamente, siempre se puede realizar el análisis de la comunidad epistémica pertinente que está detrás, es decir, arraigada en un determinado "paradigma", en el lenguaje de Kuhn, o "conjetura plausible", o "suposición fecunda", en los términos de Popper. Pareciera que nadie puede salvarse de esta Arca Caudina de la comunidad epistémica subyacente que más bien refiere el análisis a la sociología del conocimiento. Con ello se incomoda a algunos, pues se descubren y se desnudan rutas internacionales de extensión de aval dentro de una determinada corriente interpretativa, que más bien parecen cadenas de reproducción de cuadros perfectamente diseñadas. Imagen lejana con mucho del ideal de la selección voluntaria o por capacidad ${ }^{\circ}$ de una vía intelectual.

5 Virendra Shekhawat lleva adelante una comparación detallada entre las técnicas de teorización en general del Occidente contemporáneo y las de la India. El pensamiento Darsana considera de vital importancia un periodo de introspección que permita arribar a la intuición como insumo de la actividad teórica. Puede consultarse Shekhawat, Virendra, "Dos técnicas de teorización", en Diogenes, revista trimestral, número 116-117, invierno-primavera, Universidad Nacional Autónoma de México; 1981-1982.

6 Para un estudio detallado de caso sobre la reproducción de cuadros puede con- 
Debe recordarse en todo momento que la validez paradigmática o lo fecundo de una suposición se sustenta en cierta medida en un acto de aproximación sucesiva $y$, en última instancia, en una negación: para un momento determinado no existe refutación, lo que no quiere decir que tal o cual afirmación sea irrefutable. La mayor fecundidad se reconoce en una matriz de interpretación a partir del supuesto de que se ha expuesto el fenómeno a las diversas matrices existentes, cuestión que, por desgracia, no siempre es cierta y que enmascara la labor científica que se concibe de forma ideal como enfrentamiento permanente y. total.

Por otro lado, pareciera existir una diferencia de dinámicas en las comunidades epistémicas. Se da en el extremo el caso de comunidades en permanente crisis de formulación y poca actividad de confirmación de la matriz disciplinaria imperante y, en el otro, comunidades epistémicas que descartan cualquier planteamiento que venga a sacudir la matriz. Las variables tienen que ver con factores socio-ecónómicos, con la edad de las comunidades en doble lectura, es decir, en el nivel individual y en el nivel de comunidad.

Además, uno de los muy esperanzadores mitos de estabilidad paradigmática que se sustenta en la ampliación del marco de información manejable tampoco pareciera cobrar mayor sustento hoy en día, pues lo que se pensó que daría fuerza, la extensión de la base informativa, aumentó paralelamente el grado de vulnerabilidad de las matrices disciplinarias. Los mótivos de tal vulnerabilidad son varios. En primer lugar, hay una variación importante en el marco histórico debido a que la extensión de la actividad de investigación científica ha proliferado, sobre todo en determinados países gracias a bancos de información antes inalcanzables. La empresa cientifico-acumulativa, típica del siglo $\mathrm{xrx}$, parece como si quisiera ser sustituida por una rápida reformulación de pequeñas matrices disciplinarias casadas con una dinámica informativa en plena implosión y explosión.?

A la par, este mecanismo de explicación del conocimiento, arraigado en el sujeto y en el aval comunitario, ha permitido ampliar el panorama endurecido de lo que es el conocimiento a esferas que la academia del diecinueve negó. Ahora se mira el conocimiento en una perspectiva rejuvenecida, que acepta la existencia de parámetros diferentes de sapiencia y conocimiento que demandan una explicación epistemológica

sultarse: Baudelot, Christian y Roger Establet, La escuela capitalista, Siglo XXI Editores, S. A., México, D. F., primera edición, 1975.

7 Kuhn aborda desde varias perspectivas la agitación de los paradigmas en un texto de recopilación de estudios, en particular el duodécimo "Algo más sobre los paradigmas", Kuhn, T., La tensión esencial, Fondo de Cultura Económica, Consejo. Nacional de Ciencia y Tecnologia, México, D. F., 1982. 
clara, precisa y rigurosa, en extraño ejercicio de la conciencia al que anteriormente hicimos mención. Se trata en esta vía de articular una forma explicativa de posibles formas del conocimiento, explicación certera en sus estructuras, hermenéuticas y teóricas, que nos permita conocer una forma de conocimiento. ${ }^{8}$

Uno de los vehículos de explicación social más común y extendido es, sin duda, la articulación conceptual que surge del llamado discurso político. Este fenómeno de articulación de respuestas expresas permanentemente al foro público, contiene varios ejes analíticos. Uno de los asideros más fuertes en el estudio de la producción de conocimiento contemporáneo y, en particular, del discurso, es el que se refiere a la pretensión del sujeto cognoscente como piedra de toque para poder comprender la motivación central en una determinada relación de conocimiento entre el sujeto cognoscente y el objeto de estudio. Recordemos que la explicación arraigada en el sujeto cognoscente es punto de partida que permite arrojar luz sobre las otras formas de conocimiento social. En todo caso, se trata aquí también de una "conjetura plausible" o "suposición fecunda" para el análisis."

Este hilo conductor nos permite separar dos grandes conjuntos de sujetos cognoscentes abocados a la explicación del fenómeno político. En el primer conjunto se encontrarfan aquellos sujetos que explicitamente se abocan a una labor teórica, es decir, de armazón conceptual y hermenéutica para explicar el fenómcno político. El segundo conjunto agrupa de manera inesperada un largo listado de reconocidos pensadores polfticos, cuyas conceptualizaciones siguen teniendo vigencia explicativa a pesar de hacer referencia a situaciones históricas muy concretas y de no tener una pretensión teórica. La pretensión teórica que tha estado estrechamente ligada a la profesionalización del conocimiento y, por lo tanto, a cierta modernidad en un acercamiento de explícito simplismo, de naive theory, pudiera explicarse simplemente como la intención del sujeto cognoscente por mantener una coherencia conceptual en la totalidad de un razonamiento. Vale decir que las reformulaciones conceptuales explícitas o implícitas son perfectamente válidas, siempre y cuando ellas respeten un mínimo trecho que el propio autor determina. Las acepciones múltiples no deben mirarse con desconfianza, pues ellas han permitido, a no dudarlo, acercamientos de gran riqueza sobre el fenómeno

8 Para una breve recopilación crítica de los planteamientos más recientes sobre modelos explicativos del conocimiento puede consultarse: Shekhawat, Virendra, "Tendencias Epistemológicas", Diógenes, revista trimestral, número 128, Invierno de 1985, Universidad Nacional Autónoma de México, 1985.

- Reyes-Heroles, Federico; Ensayo sobre los fundamentos politicos del Estado contemporáneo, Universidad Nacional Autónoma de México, segunda edición, 1983; en particular el "Punto de Partida". 
politico. Por ejemplo, recuérdense los usos multivalentes que del concepto Estado hace Nicolás Maquiavelo y que resultarían perfectamente ininteligibles si partimos del supuesto de pretensión de limpieza hermenéutica. Por ello, el listado de aquellos autores que realizaron acercamientos fructiferos sobre tal fenómeno se enriquece infinitamente al permitir la multivalencia conceptual que permita incluir ensayistas politicos, periodistas políticos ${ }^{10} \mathrm{y}$, por supuesto y de manera fundamental, al discurso político como venero innegable de conceptualizaciones.

Observadas estas actividades en conjunto, en particular en el análisis del fenómeno político, parecieran tener una dinámica nuclear propia. Las pretensiones del sujeto cognoscente abocado al discurso político se desfasan por completo de los parámetros de las comunidades epistémicas pertinentes propias del mundo académico. Sin embargo, esto no quiere decir que ellas no puedan ser presentadas de manera orgánica. Caminando un poco más allá, es evidente que las comunidades epistémicas pertinentes, productoras de teoría política, recogen a menudo conceptualizaciones que provienen del género discursivo, al igual que el discurso retoma suposiciones que se desprenden del marco académico.

En otro lugar ${ }^{11}$ hemos tratado de establecer una diferenciación en las motivaciones y parámetros de las diferentes producciones de conocimiento. El parteaguas analftico logró establecerse a partir de una diferenciación de implicaciones de dos formas de conocimiento en coexistencia simultánea, y que por ello reclaman a la par vigencia. Por esto hablamos de dos presentes. Se trata de dos formas de entendimiento y explicación social desfasadas en sus mecanismos de reconocimiento social y en sus pretensiones originales que abordan un fenómeno similar sólo en apariencia.

El primer presente surge de una forma de conocimiento social muy extendida en la cual el sujeto cognoscente intenta aprehender y explicar un determinado fenómeno político en el momento mismo en que éste históricamente se suscita. Las motivaciones centrales de este sujeto cog. noscente, de carácter histórico, son las de dar una explicación coherente dentro de una determinada matriz discursiva, que no académica. Estas formas de conocimiento, entre las cuales se encuentran las matrices discursivas, surgen con frecuencia, por ejemplo, de los líderes y caudillos que participan en una determinada movilización política y que van buscando explicaciones sobre la marcha. Ellos retoman un determinado

10 Para una aplicación especffica de los planteamientos del Ensayo sobre los fundamentos politicos del Estado contempordneo, al periodismo polftico puede consultarse: Reyes-Heroles, Federico, Anclajes, Ediciones Océano, S. A., México, D. F., 1985, en particular la "Presentación".

11 Ensayo sobre..., "Punto de Partida". 
marco axiológico y de interpretación y le dan forma discursiva con cierta coherencia hasta donde ello es posible. La pretensión central aquí es de impacto y movilización, no de veracidad o cientificidad. Es justamente en el segundo presente que el sujeto cognoscente se mueve en estas dos últimas coordenadas. Por un lado la veracidad, es decir, que una determinada noción esté asentada en un sano margen en las corroboraciones fácticas e históricas, dentro de una matriz académica que una determinada comunidad epistémica retome y avale. Por el otro, la cientificidad, no desposeída de su bagaje positivizante, que demanda información engarzada en tendencias históricas más o menos comprobables. El tipo de afirmaciones que surgen en este segundo momento del conocimiento social para el fenómeno político, tienen un rango de aplicabilidad mayor y pueden pretender tener un carácter acumulativo. Para lograrlo, sin embargo, el sujeto cognoscente tiene que recurrir a una proyección temporal que lo desfasa del suceso. Se trata de pretensiones distintas que desembocan en actividades sociales totalmente diferenciadas. La aspiración académica encadena al sujeto cognoscente que quiera proceder con garantía en sus afirmaciones, a utilizar, en exclusiva, aquellos conceptos cabalmente confirmados y reconocidos por una comunidad epistémica. El primer presente, en cambio, libera de ese grillete pero, a la vez, orilla al sujeto a una forma de conocimiento riesgosa que es la única que le permite abordar el fenómeno a tiempo.

El carácter mismo del fenómeno político pareciera haber provocado una forma de conocimiento especial, socialmente existente, no producto de una definición conceptual a priori. Aquel que pretenda que su conceptualización esté montada sobre el suceso, difícilmente podrá recurrir a afirmaciones corroboradas por vía de paradigma. El sujeto se mueve en el primer presente, no pretende veracidad, pero necesita afirmar sobre lo que en ese momento adquiere el estatuto de real. (Recordemos la diferencia entre Wahrheit y Realität.) La matriz a la que se tiene que justificar o criticar se distingue de las matrices disciplinarias en que se sustenta con frecuencia en declaraciones axiológicas, valorativas que constituyen el leit motiv de tales matrices.

Ahora bien, dado que el fenómeno político está estrechamente vinculado al de conducción social, el componente propositivo en las matrices discursivas es mucho más común que en las matrices disciplinarias. De esa caracteristica surge otro de los rasgos definitorios de las matrices discursivas frente a las disciplinarias. Las matrices de discurso polf́tico están en permanente exposición pública. Nos referimos aquí no sólo a la exposición frente a otras matrices discursivas, en'frentamiento que es bastión institucional de los regimenes democrático-plurales, sino al ma- 
yor de los jueces que es aquel que ha sido movilizado, impactado por vía del discurso político y al cual se le han generado expectativas.

Observando el asunto desde la perspectiva de los riesgos de degradación, dadas las diferentes tendencias que se encuentran subyacentes tanto en la matriz disciplinaria como en la matriz discursiva, pareciera que la primera, a partir de las características de las comunidades epistémicas que llevan a cabo la evaluación que pretende ser veraz, científica o profesional, tiende a anquilosarse con facilidad. Lo que se ha dado en llamar comunidades epistémicas pertinentes, en el caso de la producción académica típica, se arraigan mucho más en la confirmación de la veracidad de una suposición fecunda, que en el cuestionamiento y recuperación de aquellas variables de la información que distorsionan la funcionalidad de una determinada matriz. Probablemente la explicación al respecto pueda encontrarse en las propias funciones de formación de cuadros que dichas comunidades realizan a la par y la forma en que las biografías individuales se insertan en las instituciones.

Por su lado, las matrices discursivas, por la función social de movilización, de constitución y mantenimiento gubernamental de la acción estatal que les corresponde, parecieran incurrir justamente en tendencias inversas a las de las comunidades epistémicas del mundo académico. Si la motivación fundamental es la movilización, más que la coherencia discursiva o la veracidad, no deberá causar asombro que el discurso político se acerque a las apreciaciones de sentido común, es decir, aquellas en las cuales el sujeto cognoscente arroja conceptos de manejo no especializado y puede también resbalar en niveles míticos ${ }^{12}$ en busca de apoyo: Intento de racionalización dentro de una determinada matriz discursiva que se substituye por interrogantes o afirmaciones que dejan de apoyarse en las interpretaciones de los hechos, para pasar a invocar teleologias insuperables, o tiempos mfticos, etc. Retómese, como ejemplo, el discurso político del Tercer Reich ${ }^{13}$ que si bien en un inicio se sustentó en toda una recomposición de la quebrantada economía alemana, poco a poco fue perdiéndose cada vez más en interpretaciones míticas.

Otra característica de la matriz discursiva es, sin duda, su alto contenido utópico. ${ }^{14}$ Mientras que en la producción de conocimiento, susten-

12 Un texto de reciente edición en español que puede consultarse como introducción al tema de los mitos en las teorias y discursos políticos es el de Reszler, André, Mitos políticos modernos, Fondo de Cultura Económica, Colección Popular, México, 1984 .

13 Un texto tradicional para el estudio de la conformación del nacional-socialismo es sin duda el de Neumann, Franz, Behemoth, Fondo de Cultura Económica, primera edición, México, 1984.

14 Ensayo sobre los..., capítulo VI. 
tada por las comunidades epistémicas pertinentes del mundo ácadémico, la mayoría de las veces se demanda el vacío absoluto de contenidos utópicos a la par que se exige la sustentación de cualquier supuesto, en las matrices discursivas el elemento utópico casi siempre está presente. En otro lugar hemos desarrollado el concepto idea de vida ${ }^{15}$ que, precisamente, hace referencia a esa carga propositiva y parcialmente utópica presente en las matrices del primer presente. Cualquier movilización social que se encauce en la transformación o reforma de una determinada situación tendrá que proponer alternativas que den razón de ser a la acción o movilización. Incluso se puede llegar al extremo de solicitar o exigir el aniquilamiento del representante individual, es decir, la presencia de una idea de vida que le demanda al sujeto la muerte física, en el entendido de lograr con ello una mejor forma de vida. ${ }^{16}$ Las matrices disciplinarias no tienen esta preocupación.

Ahora bien, la cuestión se vuelve más compleja cuando se intenta establecer cuales son los mecanismos que sustentan la calidad de real en una matriz de interpretación discursiva. Habíamos discernido con anterioridad el sentido de las afirmaciones veraces. Dijimos que tal calidad era otorgada, la mayoría de las ocasiones, por una comunidad epistémica pertinente sustentada en una "conjetura plausible" o "suposición fecunda", que pueda mostrar que las anomalías interpretativas dentro de una matriz especifica son las menos, frente a un predominio de los sucesos que encuentran explicación satisfactoria en esa misma matriz. También hemos señalado la tendencia de los núcleos académicos a llevar adelante una labor acumulativa de los casos de confirmación más que de las anomalías. En otro trabajo hemos señalado la casi nula actividad de abocar esfuerzos de recopilación de información para promover la historia de lo no historiado. En fin, el hecho es que las comunidades continúan con una recopilación que busca confirmar hasta que viene un quebrantamiento verdaderamente insostenible.

La situación de las matrices discursivas políticas es otra, pues puede llegar el caso de rectificaciones conceptuales de importancia dentro de una matriz, riesgosas desde la perspectiva doctrinal, pero que se hacen necesarias a partir de la mediación insalvable que es la exposición pública del discurso político. Vayamos a las situaciones extremas para tratar de encontrar, por contraste, el medio justo. El discurso político es producto de la interpretación fundamentalmente social, ya que, por lo menos en su nacimiento, es una necesidad social de articulación de necesidades e inquietudes que se trasmiten de un individuo a otro para 
después cobrar otra dimensión. ${ }^{17} \mathrm{El}$ discurso político puede después convertirse en productor de un determinado hecho social. Por ejemplo, existen situaciones de levantamientos. políticos súbitos en los cuales brota una determinada interpretación de ilegitimidad de un régimen, interpretación que jamás ha sido expuesta públicamente, y que, sin embargo, prende como en un incendio de pradera, provocando una movilización que ventila determinadas interpretaciones y pasa a formar una matriz discursiva, más o menos articulada que, a su vez, es asimilada por la población. Ese discurso político, esa interpretación de los hechos, ya se encontraba en la sociedad de la que se trate, así no hubiera habido exposición pública. Es una interpretación social nacida del sentido común, no tamizada por una comunidad epistémica, o sapiencial, o política.

Por ejemplo, se ha encontrado un hilo conductor de índole anarquista en los levantamientos campesinos. Absurdo sería pensar una cultura anarquista en los campesinos. En cambio, el fenómeno puede encontrar explicación por la visión mítica de la utopía campesina. Sin embargo, el hecho concreto es que una revisión documental llevaría a afirmar la participación más o menos frecuente de pensamiento anarquista en los levantamientos campesinos. Éste sería el primer extremo: una concepción política, una forma de conocimiento ampliamente legitimada, que se confirma por la movilización que, sin embargo, no tenía representante formal en el foro público.

El otro extremo es el de una exposición reiterada en un discurso político finamente articulado que, sin embargo, no logre movilización. En ese momento se cuenta con una matriz discursiva que puede estar avalada de manera amplia por comunidades sapienciales de indole política y que, a pesar de ello, ha caido en una dogmática propia que le impide establecer vínculos con la sociedad de que se trate. La movilización es contemplada en este esquema no exclusivamente como un acto de masas, sino como una de las manifestaciones de un fenómeno con expresiones múltiples que parten del lector anónimo. El impacto es comprobable por vía fáctica.

Las matrices discursivas oscilan, entonces, en una suerte de reconocimiento de los valores, inquietudes e interpretaciones que socialmente imperan y la posibilidad de arraigar nuevos valores, en ocasiones pro-

17 En otro texto nos hemos abocado a un breve análisis del fenómeno de la oposición dentro del esquema del Ensayo sobre los fundamentos politicos del Estado contemporáneo. Los requisitos para la articulación del discurso ya sea de oposición, o el que esgrime la acción estatal, en parte están determinados por el foro público. Puede consultarse: Reyes-Heroles, Federico, Poltica y administración a través de la idea de vida, Instituto Nacional de Administración Pública, Serie Praxis núm. 58; en particular el capitulo IV, "La oposición y el gobierno en acción", México, D. F.; 1983. 
pios de la matriz discursiva. Se puede establecer una dinámica hecho-interpretación-respuesta-conducción. Al igual que en el planteamiento de T. Kuhn sobre los periodos de normalidad y críticos para los paradigmas científicos, las matrices discursivas también atraviesan por periodos de inestabilidad y de reacomodo que son, en parte, producto de la necesaria exposición en busca de apoyo o legitimación. Una matriz discursiva no dinámica es una matriz ahistórica.

Otra de las caracteristicas distintivas de la matriz discursiva frente a la producción de comunidades epistémicas con pretensiones académicas es el hecho de que estas últimas encuentran una motivación central en la precisión del origen de una afirmación y de la posible exactitud de una consecuencia previsible. En cambio la matriz de interpretación discursiva tiene en esta articulación fina un enorme riesgo, pues las anomalías resaltarían, en la permanente exposición pública, de manera inocultable: riesgo de mucho menor monto en el mundo de las comunidades epistémicas con pretensión académica. Las matrices discursivas apuntan a los grandes derroteros, dejando de lado la pretensión de ser precisas, ejercicio de muy poca utilidad y enormes riesgos en la función que realizan en la acción estatal.

Por este conducto, las nociones de matriz discursiva y realidad se casan en maridaje quizá tan estrecho como el de las matrices disciplinarias con la veracidad. Lo que también resulta concluyente es que una y ôtra vertiente del conocimiento justifican su forma y razón de ser en función del objeto de estudio que se plantean y de las pretensiones de los sujetos que participan en cada una de las actividades sociales de las que son producto. También es evidente que la dicotomfa maniquea entre el discurso político y verdad es un simplismo no productivo. 